\title{
SBE13, a newly identified inhibitor of inactive polo-like kinase 1
}

\author{
Sarah Keppner ${ }^{1 *}$, Ewgenij Proschak², Gisbert Schneider ${ }^{2}$, B Spänkuch ${ }^{1}$ \\ From 5th German Conference on Cheminformatics: 23. CIC-Workshop \\ Goslar, Germany. 8-10 November 2009
}

Protein kinases are important targets for drug development. The almost identical protein folding of kinases and the common co-substrate ATP leads to the problem of inhibitor selectivity. Type II inhibitors, targeting the inactive conformation of kinases, occupy a hydrophobic pocket with less conserved surrounding amino acids [1].

Human polo-like kinase 1 (Plk1) represents a promising target for approaches to identify new therapeutic agents. Plk1 belongs to a family of highly conserved serine/threonine kinases, and is a key player in mitosis, where it modulates the spindle checkpoint at metaphase/anaphase transition. Plk1 is over-expressed in all today analyzed human tumors of different origin and serves as a negative prognostic marker in cancer patients. The newly identified inhibitor, SBE13, a vanillin derivative, targets Plk1 in its inactive conformation [2]. This leads to selectivity within the Plk family and towards Aurora A. This selectivity can be explained by docking studies of SBE13 into the binding pocket of homology models of Plk1, Plk2 and Plk3 in their inactive conformation.

SBE13 showed anti-proliferative effects in cancer cell lines of different origins with $\mathrm{EC}_{50}$ values between $5 \mu \mathrm{M}$ and $39 \mu \mathrm{M}$ and induced apoptosis. Increasing concentrations of SBE13 result in increasing amounts of cells in $G_{2} / M$ phase 13 hours after double thymidin block of HeLa cells. The kinase activity of Plk1 was inhibited with an $\mathrm{IC}_{50}$ of $200 \mathrm{pM}$.

Taken together, we could show that carefully designed structure-based virtual screening is well-suited to identify selective type II kinase inhibitors targeting Plk1 as potential anti-cancer therapeutics.

${ }^{1}$ Goethe-University, Medical School, Department of Gynecology and Obstetrics, Theodor-Stern-Kai 7, 60590 Frankfurt, Germany

\section{Author details}

'Goethe-University, Medical School, Department of Gynecology and

Obstetrics, Theodor-Stern-Kai 7, 60590 Frankfurt, Germany.

${ }^{2}$ Goethe-University, Frankfurt, Germany.

Published: 4 May 2010

\section{References}

1. Liu Y, Gray NS: Nat Chem Biol 2006, 2:358-364.

2. Keppner S, Proschak E, Schneider G, Spänkuch B: Chem Med Chem 2009.

\section{doi:10.1186/1758-2946-2-S1-P54}

Cite this article as: Keppner et al: SBE13, a newly identified inhibitor of inactive polo-like kinase 1. Journal of Cheminformatics 2010 2(Suppl 1):P54.

\footnotetext{
Publish with ChemistryCentral and every scientist can read your work free of charge

"Open access provides opportunities to our colleagues in other parts of the globe, by allowing anyone to view the content free of charge." W. Jeffery Hurst, The Hershey Company.

- available free of charge to the entire scientific community

- peer reviewed and published immediately upon acceptance

- cited in PubMed and archived on PubMed Central

- yours - you keep the copyright

Submit your manuscript here:

http://www.chemistrycentral.com/manuscript/

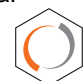
Chemistry Central
} 